\title{
Desenvolvimento local e a construção de uma nova territorialidade: a implantação do Programa Territórios da Cidadania no Norte Pioneiro do Paraná
}

\author{
Eliana B. M. Lopes ${ }^{1}$ e Maria Teresa Miceli Kerbauy ${ }^{2}$
}

RESUMO: A abordagem territorial do desenvolvimento assumiu lugar de destaque nas políticas públicas estatais, norteando também ações origináarias de distintas organizações da sociedade. O enfoque territorial, influenciado pelas análises relacionadas aos distritos industriais, destaca-se como uma forma específica de tratar processos e situações delimitadas espacialmente. No Brasil, a Secretaria de Desenvolvimento Territorial, vinculada ao Ministério do Desenvolvimento Agrário, desde 2003, o adota-o estrategicamente por meio do Programa Nacional de Desenvolvimento Sustentável dos Territórios Rurais (PRONAT). Em 2008, ocorreu a implantação do Programa Territórios da Cidadania, um desdobramento do PRONAT e das políticas de desenvolvimento rural direcionadas à dinamização de territórios deprimidos, constituídos por pequenos municípios e que, compreendem áreas e atividades rurais e urbanas, superando a ênfase setorial do mundo rural. A análise dos pressupostos subjacentes à adoção dessa estratégia nas políticas de desenvolvimento rural no Brasil, realizada por meio do estudo da constituição do Território Integração Norte Pioneiro (PR), indica que a ênfase dessa política recai mais sobre a efetividade da descentralização do que a concretização da gestão social.

PALAVRAS-CHAVE: territórios, abordagem territorial do desenvolvimento, PRONAT, Programa Territórios da Cidadania, Território Integração Norte Pioneiro.

ABSTRACT: The territorial approach of development took an important place in the public politics of the State, also guiding the actions originated from different organizations of the society. The territorial focus, influenced by the analysis related to the industrial districts, is highlighted as a specific form to dealing with process and situations spatially delimited. In Brazil, the Secretary of Territorial Development, linked to the Ministry of Agrarian Development, since 2003, has adopted it strategically through the Programa Nacional de Desenvolvimento Sustentável dos Territórios Rurais (PRONAT). In 2008, had occurs the implantation of the Programa Territórios da Cidadania, a part of the PRONAT and of the rural development politic directed to the dynamization of the depressed territories constituted by small counties that cover rural and urban areas and activities, overcoming the focus on the rural world. The analysis of the assumptions underlying to the adoption of this strategy on the politic of the rural development in Brazil made through the study of the constitution of the Território Integração Norte Pioneiro (PR), which indicates that the focus of this politic falls more on the effectiveness of the decentralization than the concretization, and implementation, of the social management.

KEYWORDS: territories, territorial approach on development, PRONAT, Programa Territórios da Cidadania, Território Integração Norte Pioneiro.

Doutoranda no Programa de Pós-Graduação em Sociologia da Universidade Estadual Paulista (Unesp), campus de Araraquara, sob a orientação da professora Dra. Maria Teresa Miceli Kerbauy, bolsista CAPES. E-mail: ebml@uol.com.br.

2 Professora do Programa de Pós-Graduação em Sociologia da Universidade Estadual Paulista (Unesp), campus de Araraquara. E-mail: kerbauy@travelnet.com.br.

CADERNOS GESTÃo PÚBLICA E CIDADANIA, V. 14, N. 55 - JUL./DEZEMBRO DE 2009 


\section{Introdução}

Este artigo tem como objetivo discutir a constituição do Território Integração Norte Pioneiro do Paraná como produto de uma política pública de desenvolvimento rural, o Programa Territórios da Cidadania, vinculado ao governo federal, e analisar o modo pelo qual este processo vem se concretizando.

Além da literatura consultada, foram realizadas entrevistas com membros da Secretaria de Estado da Agricultura e Abastecimento do Paraná; com o delegado federal do Ministério do Desenvolvimento Agrário no estado; ex-prefeitos dos municípios que compõem o território; líderes sindicais e técnicos da Empresa Técnica de Extensão Rural do Paraná (EMATER). Também foram consultadas as atas das reuniões ordinárias e extraordinárias realizadas pelo Conselho Estadual de Agricultura Familiar e Desenvolvimento Rural no Paraná (CEDRAF) do Comitê de Articulação Territorial.

Em 2008, participamos de dois eventos relevantes na região: o I Fórum de Desenvolvimento Regional Sustentável, realizado em maio, em Jacarezinho; e a divulgação do estudo realizado pelo Instituto Paranaense de Desenvolvimento Econômico e Social (IPARDES), realizado em setembro, em Ibaiti, intitulado "Diagnóstico Socioeconômico do Território Norte Pioneiro Paranaense”. Em ambas as situações, conversas informais e entrevistas com representantes sindicais e técnicos da EMATER foram realizadas, possibilitando a obtenção de informações essenciais para a realização de outras entrevistas em 2009.

Nesse mesmo ano, em março, abril e junho, participamos de todas as reuniões realizadas pelo Conselho Gestor Provisório do Território Integração Norte Pioneiro. No segundo semestre, nossa atenção direcionou-se ao contato com os ex-prefeitos que participaram da constituição do Território Integração Norte Pioneiro (PR) e a obter os documentos no Conselho Estadual de Desenvolvimento Rural Sustentável (CEDRAF), no Instituto Paranaense de Assistência Técnica eExtensão Rural(EMATER) ena delegacia estadual do Ministério do Desenvolvimento Agrário (MDA).

A utilização de diversas fontes foi o método escolhido para que as informações obtidas tanto formalmente como informalmente pudessem ser confrontadas, complementadas e comparadas. Vale ressaltar que as referências teóricas consultadas permitiram que fosse estabelecido o referencial de análise e a articulação entre a proposta da política governamental e o que de fato vem ocorrendo no Território Integração Norte Pioneiro (PR).

O Paraná passou por um processo de industrialização significativo nas últimas décadas, resultando numa economia oriunda de uma política agressiva de incentivos fiscais e que se 
concentrou, sobretudo, na região metropolitana de Curitiba. No entanto, as atividades do setor primário, tanto as mais modernas como as tradicionais, são ainda bastante significativas e dispersas no interior do estado.

O norte pioneiro é uma das 10 mesorregiões que constituem o estado. Sua ocupação decorreu de uma economia predominantemente cafeeira. O aumento da produção de commodities, substituindo os cafezais, aliado à ampliou das áreas de pastagens, principalmente a partir da década de 1970, ampliou as dificuldades na absorção da mão de obra. A região, que tinha no início da década uma das maiores populações do estado, apresentou uma das mais elevadas perdas na esfera estadual ao final dos anos 1970 e nas décadas seguintes. Sua população foi reduzida praticamente pela metade entre 1970 e 2000. (IPARDES, 2004, p. 24). A dinâmica de seu crescimento populacional não apresenta tendências à reversão, sendo que

As características de sua base produtiva e a restrita perspectiva de investimentos para essa mesorregião indicam que sua condição de esvaziamento tende a perdurar nas áreas rurais, atingindo núcleos urbanos (IPEA, 2000, p. 105).

Em 1996, os 46 municípios abrangidos pela mesorregião possuíam uma densidade populacional média de 34,19 habitantes/ $/ \mathrm{km}^{2}$, polarizando-se em torno de Cornélio Procópio, Santo Antônio da Platina e Jacarezinho. Nenhum desses municípios apresentava uma população acima de 50 mil habitantes, portanto, eram considerados municípios de pequeno porte ${ }^{3}$, sendo mais da metade da população $(52,17 \%)$ em estado de transição para o urbano, e uma quantidade considerável como rural de pequena dimensão ${ }^{4}$ (IPEA, 2000, p. 103).

O norte pioneiro paranaense é caracterizado como "espacialidade com mínima relevância" (IPEA, 2000, p. 205; IPARDES, 2006, p. 14), isto é, sem expressão econômica ou institucional, sendo que as atividades econômicas atuais não parecem suficientes para provocar melhorias nas condições sociais da população, o que tende a reforçar o esvaziamento tanto de áreas urbanas como rurais.

\footnotetext{
3 Segundo o Censo Demográfico de 2000, apenas cinco municípios paranaenses possuem população acima de 20 mil habitantes.

4 No final da década de 1990, o Instituto de Pesquisas Econômicas Aplicadas (IPEA), em parceria com outras instituições, empreendeu estudos para a caracterização da rede urbana brasileira, entendida como o "conjunto de cidades que polarizam o território brasileiro e os fluxos de bens, pessoas e serviços que se estabelecem entre eles” (IPEA, 2000, p. 36). A tipologia dos municípios estabelecida considera que são municípios rurais aqueles com grau de urbanização inferior a 50\% e atividades centradas no setor primário. Já os que estão em fase de transição para o urbano apresentam grau de urbanização superior a 50\%. Em relação aos municípios de média e grande dimensão, pode-se verificar que são aqueles municípios que apresentam uma população superior a 50 mil habitantes e um grau de urbanização acima de 75\%, além de possuir atividades focadas na indústria e no comércio (IPEA, 2000, p. 57).
} 
Com o objetivo de estancar e reverter esse processo, assim como buscar melhorias nos indicadores econômicos e sociais, em geral abaixo da média estadual, a Empresa Técnica de Extensão Rural do Paraná (EMATER), vinculada ao governo do estado, vem atuando na região desde 2000 e em algumas áreas de forma conjunta com a Federação de Trabalhadores da Agricultura do Paraná (FETAEP).

As propostas de intervenção direcionaram-se à integração das atividades agropecuárias presentes em municípios contíguos visando ao fortalecimento e à dinamização das cadeias produtivas. Inicialmente denominadas Áreas de Programação Integrada (API), as ações focadas no processo produtivo e nas articulações intermunicipais gradativamente incorporaram outros aspectos ao buscar modificações nas condições das áreas de saúde, educação etc. A configuração inicial do conjunto de municípios abrangidos não se alterou até bem recentemente, mas a ampliação das ações empreendidas depois de 2000 possibilitou a transformação das API em Áreas de Desenvolvimento Integrado (ADI).

As diversas atividades desenvolvidas nessas áreas foram compreendidas como iniciativas territoriais consubstanciadas em uma concepção de território que entende ser este o ponto de partida que tem como resultado uma construção social. A referência a esta concepção remete à abordagem territorial do desenvolvimento, entendida, por sua vez, como subsídio às intervenções para a promoção do desenvolvimento rural e que consiste em um conjunto de orientações teórico-metodológicas que adquire relevância, principalmente a partir da década de 1990, nos países desenvolvidos.

No âmbito da mesorregião do norte pioneiro paranaense, quatro iniciativas territoriais se constituíram e, posteriormente, com a sua integração, formaram o Território Integração Norte Pioneiro. Abrangendo um total de 27 municípios, as três primeiras tiveram participação ativa da FETAEP:

1) Território Vale do Rio das Cinzas, constituído por sete municípios: Jundiaí do Sul, Conselheiro Mairinki, Ibaiti, Japira, Jaboti, Tomazina e Pinhalão. Os trabalhos iniciaram-se no final de 2005 com a participação da EMATER e da FETAEP. O Consórcio Intermunicipal para o Desenvolvimento do Território do Vale do Rio das Cinzas (CIVARC) encontra-se formalizado desde junho de 2007;

2) Território Divisa Norte: a EMATER definiu, em 2002, cinco municípios - Salto do Itararé, Siqueira Campos, Santana do Itararé, Wenceslau Braz e São José da Boa Vista -, como constitutivos de uma Área de Programação Integrada (API) e, em 2004, a partir de um convênio estabelecido com a FETAEP, foram incentivados projetos intermunicipais. Os municípios estão negociando a formação de um consórcio; 
3) Território G5: resultado de uma parceria entre a EMATER e a FETAEP, iniciada em 2005, para promover projetos intermunicipais. Os cinco municípios que o compõem - Ribeirão Claro, Carlópolis, Joaquim Távora, Guapirama e Quatiguá - estão em processo de formalização do consórcio intermunicipal;

4) Território Nordeste: resultado de ações da EMATER empreendidas em quatro municípios desde 2003, no âmbito das API, e agregou outros municípios nos anos seguintes. Em 2005, dez municípios integraram o Território formalizado, recentemente, no Consórcio Público Intermunicipal de Desenvolvimento do Território Nordeste do Estado do Paraná (CODENOP). Os municípios que compõem essa iniciativa são Santa Amélia, Abatiá, Nova Fátima, Ribeirão do Pinhal, Santa Cecília do Pavão, Santo Antonio do Paraíso, Congoinhas, Nova Santa Bárbara, São Jerônimo da Serra e Sapopema.

Em 2003, primeiro ano do governo de Luiz Inácio Lula da Silva, foi criada a Secretaria de Desenvolvimento Territorial (SDT), vinculada ao Ministério do Desenvolvimento Agrário (MDA), com o objetivo de executar o Programa Nacional de Desenvolvimento Sustentável de Territórios Rurais (PRONAT), implementado no mesmo ano. O foco dessa política territorial foi, e continua sendo, a execução de um conjunto de ações direcionadas à reunião de municípios rurais articulados territorialmente para promover seu desenvolvimento sustentável.

As finalidades desse Programa têm como pressupostos a diminuição da pobreza, a geração de emprego e renda, a preservação do meio ambiente, o estímulo ao empreendedorismo e a formação de arranjos produtivos locais, além do incentivo à participação da sociedade em novos arranjos institucionais em âmbito intermunicipal.

Foram, e são contemplados pelos recursos do PRONAT, os territórios reconhecidos com essas características na esfera estadual. Após uma primeira articulação entre os municípios, faz-se necessária a sua homologação nos conselhos estaduais de desenvolvimento rural, para que possam ser incluídos efetivamente na esfera federal como territórios, permitindo, assim, a consolidação de uma cooperação intermunicipal.

Membros do governo do Estado do Paraná e dos próprios representantes do MDA no estado sugeriram que, em função de existirem limites numéricos para o reconhecimento dos territórios em cada esfera estadual, as iniciativas territoriais no norte pioneiro paranaense deveriam integrar-se em um único território.

Esta proposta foi respaldada pela política territorial adotada pelo governo do Paraná, consubstanciada no Projeto de Inclusão Social e Desenvolvimento Rural Sustentável, 
concebido em 2005, por meio das Secretarias de Estado da Agricultura e do Abastecimento (SEAB) e do Planejamento e Coordenação Geral (SEPL), e que também incorporou as noções de multissetorialidade e a superação da oposição entre rural e urbano para a promoção do desenvolvimento rural. O projeto, atualmente ainda em fase de negociação com o Banco Mundial para a obtenção de recursos para a sua execução, compreende ações em oito territórios do estado e 127 municípios que compõem o “centro expandido”, área prioritária para as ações estatais e que visam à redução da pobreza no estado e à minimização dos desequilíbrios intrarregionais (IPARDES, 2007).

A configuração territorial estabelecida pelo governo do Estado do Paraná passou por redefinições com o objetivo de convergir com a estratégia territorial adotada pelo MDA para o estado e este, por sua vez, também trabalhou de modo a consolidar esta identificação, estabelecendo uma convergência no estabelecimento de um recorte espacial-territorial que contemplasse o mesmo conjunto de municípios ${ }^{5}$.

Perspectivas convergentes no âmbito estatal, nas esferas federal, estadual e municipal, culminaram na homologação, em 26 de outubro de 2007, do Território Integração Norte Pioneiro. Naquela ocasião, ainda não faziam parte de sua composição os municípios de Santo Antônio da Platina e Jacarezinho, regionalmente mais relevantes do ponto de vista econômico, político e de prestação de serviços.

Ressalte-se que, naquele momento, ainda que se aventasse a possibilidade, por parte dos representantes municipais vinculados às iniciativas territoriais do norte pioneiro paranaense, assim como pelas organizações ali situadas e/ou atuantes, de futura inclusão do Território Integração Norte Pioneiro no Programa Territórios da Cidadania, o objetivo inicial era o acesso aos recursos disponibilizados por meio do PRONAT, o que exigia a homologação como território pelo CEDRAF.

Em 2008, o governo federal lançou o Programa Territórios da Cidadania. A política direcionada aos territórios rurais se manteve, por meio do PRONAT. No entanto, foram priorizadas determinadas áreas para um esforço concentrado visando à transformação desses territórios deprimidos em áreas dinâmicas. A seleção desses espaços ocorreu a partir de indicadores sociais e econômicos territoriais mais baixos em relação às médias nacionais e estaduais.

Dessa forma, os territórios incorporados pelo Programa Territórios da Cidadania tiveram atenção reforçada por parte dos distintos entes estatais, os quais focaram a destinação de

5 Informações obtidas em entrevista com o delegado federal do Ministério do Desenvolvimento Agrário (MDA) no Paraná, Reni Denardi, e com Luiz Lopes, chefe do departamento de Desenvolvimento Rural, vinculado à Secretaria de Agricultura e Abastecimento (SEAB) do Paraná. 
recursos financeiros e humanos para incentivar o associativismo e o desenvolvimento de projetos de forma cooperativa.

No Estado do Paraná, de um total de sete territórios homologados pelo CEDRAF, apenas quatro poderiam ser contemplados por este Programa (sendo dois no primeiro ano, 2008; e dois no segundo, 2009). Dessa forma, em 2008, foram contemplados os territórios Vale do Ribeira e Cantuquiriguaçu e, em 2009, os territórios Paraná Centro e Integração Norte Pioneiro.

Um esforço conjugado por parte de alguns prefeitos municipais do norte pioneiro com outras lideranças políticas regionais (bem como com os técnicos da EMATER e FETAEP) foi empreendido de modo a obter a inserção do Território Integração Norte Pioneiro no Programa Territórios da Cidadania.

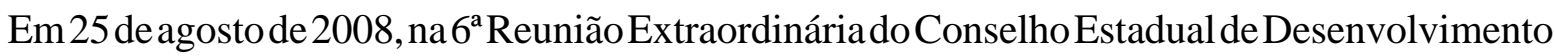
Rural e Agricultura Familiar (CEDRAF) foram reconhecidos os dois territórios que seriam incluídos nessa política a partir de 2009: o Território Paraná Centro e o Território Integração Norte Pioneiro. Ambos encontram-se situados na região considerada como alvo de ações prioritárias do Estado do Paraná, o centro expandido. Nessa mesma reunião, discutiu-se a necessidade de se incluírem os dois municípios que polarizam os outros 27 abrangidos pelo Território, no caso, Santo Antônio da Platina e Jacarezinho, para que se efetuasse, segundo o presidente do CEDRAF e Secretário de Estado da Agricultura e Abastecimento (SEAB), Valter Bianchini, “um desenvolvimento harmonioso na região” (CEDRAF, 2008).

Assim, os maiores e mais dinâmicos municípios próximos a Santo Antônio da Platina e Jacarezinho foram incluídos formalmente no Território Integração Norte Pioneiro pelo CEDRAF em 26 de novembro de 2008 e considerados “cidades tipicamente rurais", conforme observação do titular da pasta da SEAB, no Paraná. É importante observar que essa incorporação contemplava interesses do Estado do Paraná em sua política de desenvolvimento territorial, por meio de seu Projeto de Inclusão Social e Desenvolvimento Rural Sustentável, denominação atualmente modificada para Projeto Inclusão e Desenvolvimento Territorial (IPARDES, 2009).

Nosso argumento é de que a formulação do PRONAT, assim como o Programa Territórios da Cidadania, teve como objetivo a constituição de uma esfera decisória microrregional que atuasse incisivamente nas questões rurais, pois estas, em grande parte, constituíam prerrogativa da União e, de modo mais restrito, dos estados.

Nesses Programas, foi priorizada a descentralização das atribuições no que concerne ao desenvolvimento rural, entendido de forma multidimensional e multissetorial. A agregação

CADERNOS GESTÃo PÚBLICA E CIDADANIA, V. 14, N. 55 - JUL./DEZEMBRO DE 2009 
de municípios rurais em conjuntos mais amplos situados entre a esfera estadual e municipal favoreceu a criação de novos arranjos institucionais que podem reportar-se diretamente à esfera federal, o que consiste em uma estratégia de descentralização e, ao mesmo tempo, de minimização dos riscos das práticas clientelistas, sendo os recursos destinados ao território, e não para municípios específicos. Dessa forma, pressupõe-se o estabelecimento de uma prática de controle mútuo por parte dos próprios membros do Conselho Gestor Territorial, dificultando-se, assim, a concessão de privilégios para um ou outro município, ou para conjuntos parciais deles.

Os processos de descentralização política dependem de uma série de condições prévias (históricas, sociais, econômicas) que são específicas do lugar e que podem se concretizar com a participação mais ou menos ativa da sociedade e, juntamente com a qualidade das formas associativas, são fundamentais para a efetividade da gestão social, um dos pilares das propostas de desenvolvimento territorial. A descentralização nesses casos possibilita o compartilhamento das decisões entre a sociedade e o estado, impedindo que a sociedade assuma um papel coadjuvante. Os governos estaduais, nesse contexto, são considerados intermediadores necessários no reforço do pacto federativo, mas assumem ações de cunho mais complementar que propositivo.

No entanto, o acompanhamento do processo que culminou na formalização do Território Integração Norte Pioneiro permitiu verificar que a descentralização em curso prioriza a transferência de atribuições na execução da política em nível territorial, sem que haja correspondência nos processos decisórios, centralizados nas esferas federal e estadual.

Para o desenvolvimento dos pontos apresentados, este artigo estrutura-se em três seções. Na primeira abordamos os pressupostos teórico-metodológicos que referenciam a abordagem territorial do desenvolvimento, ou seja, suas premissas e articulações externas e internas, enfocando, para a análise do caso brasileiro, seus vínculos com o Programa Nacional de Fortalecimento da Agricultura Familiar (PRONAF). Em seguida, são apresentados, sinteticamente, os critérios utilizados pelo Programa Territórios da Cidadania para o reconhecimento formal dos territórios, as linhas gerais para a sua operacionalização, o processo de constituição do Território Integração Norte Pioneiro do Paraná e sua redefinição em decorrência das políticas públicas estabelecidas nas esferas federal e estadual. As observações efetuadas no que dizem respeito a nossa participação nas reuniões, bem como a explicitação das informações obtidas nas entrevistas, foram de grande valia para o desenvolvimento deste item. Por último, tecemos considerações sobre as perspectivas que se apresentam para a consolidação desse espaço territorial e os obstáculos existentes. 


\section{Do local-municipal ao territorial: origens e pressupostos teórico-metodológicos}

No Brasil, a crise do Estado desenvolvimentista ocorrida nos anos 1980, a mobilização social em defesa da redemocratização e na construção de um novo marco constitucional que expressasse as demandas sociais, bem como o redesenho federativo propiciado pela Carta Constitucional de 1988 constituem elementos significativos e indicativos das mudanças que se processaram nas décadas seguintes. A institucionalização constitucional de espaços participativos possibilitou a configuração de novos arranjos com o objetivo de estreitar as relações entre sociedade e Estado rumo a uma efetiva democracia.

Os processos de descentralização político-administrativos acompanharam essas modificações e se concretizaram em um contexto internacional e nacional de reestruturação produtiva, desregulamentação do capital e intensificação da globalização. Nesse quadro, redefiniram-se tanto a configuração estatal e social como as próprias relações estabelecidas entre eles. Exemplificando as reconfigurações ocorridas, podemos citar as reformas descentralizadoras nos campos da saúde e da educação; as privatizações e a criação de Agências Nacionais Reguladoras. O incentivo à participação social de forma voluntária e assistencialista em detrimento de ações questionadoras do status quo constituíram o substrato de um discurso que previa a modernização brasileira. Concomitantemente, preocupações ambientais adquiriram maior relevância. As agências multilaterais - os meios de comunicação e os movimentos sociais - trouxeram a questão do desequilíbrio ecológico para o debate cotidiano.

No âmbito municipal, experiências ocorridas nos anos 1980 e 1990, geralmente empreendidas por políticos situados à esquerda do espectro político e incentivadoras de processos participativos e descentralizados de gestão, passaram a ser alvo de interesse de pesquisa, como o Orçamento Participativo, que se constituiu numa experiência inovadora implementada pela prefeitura de Porto Alegre. Essas iniciativas passaram a ser vistas como expressão das potencialidades e virtualidades do poder local-municipal e do seu papel fundamental para o desenvolvimento.

Por outro lado, outras posições relacionadas ao desenvolvimento local a partir da escala municipal se configuraram, durante o período, articulando-se em torno de três vertentes: a) os que entendem que, dada a fragilidade dos Estados Nacionais em decorrência do processo de globalização, cabe ao município estabelecer seus objetivos e planos de desenvolvimento local, articulando-se com outras escalas, de modo a integrar-se ao mundo globalizado. O desenvolvimento local-municipal é considerado basicamente como uma questão de 
planejamento e gestão (CASTELLS e BORJA, 1996); b) aqueles que assumem uma posição crítica com relação ao desenvolvimento local-municipal argumentando que, na realidade, este é produto de um enfoque neoliberal, que fragmenta as políticas públicas em favor das forças do mercado consoante à proposta do "Estado mínimo" (CACCIA-BAVA, 1996) e c) os que admitem que as iniciativas locais possam ser promissoras em termos de desenvolvimento, porém limitadas geográfica e socialmente se não forem articuladas no âmbito regional, nacional ou global (SANTOS, 2002; CACCIA-BAVA, 1996).

Na década de 1990, essas perspectivas diversas convergiram em torno de um consenso sobre a inviabilidade de se pensar o desenvolvimento de forma restrita, isto é, limitado espacialmente a um único município, em função da heterogeneidade socioespacial existente no Brasil. Isto porque os municípios, embora formalmente dotados das mesmas prerrogativas, dificilmente se equivalem em termos de recursos - financeiros, técnicos e políticos -, potenciais produtivos e associativos.

Além disso, a intensidade dos problemas nos centros urbanos - como transporte, moradia e segurança pública - passaram, cada vez mais, a ser tratados do ponto de vista regional, seja em função dos espaços conurbados, seja em consequência de uma proximidade que facilita os fluxos. Municípios considerados médios e grandes, populosos e economicamente dinâmicos passam a articular soluções conjuntas para as questões que se apresentam ${ }^{6}$.

Já para municípios pequenos e localizados em regiões pouco dinâmicas economicamente, surgem outras questões, como taxas de migração negativas, baixa capacidade em arrecadação de impostos, poucas opções de emprego e renda para a população residente. Geralmente associados ao predomínio de atividades ligadas ao setor primário da economia, esses municípios são comumente qualificados como rurais (VEIGA, 2003).

Em ambas as situações, gradativamente ocorrem ampliações e restrições simultâneas relacionadas aos processos de desenvolvimento: amplia-se a escala - do município para áreas mais amplas - e restringe-se a incidência dos programas governamentais ou não governamentais a partir de critérios estabelecidos como, por exemplo, o corte rural-urbano. Assim, articulações intermunicipais territoriais rurais são incentivadas e constituídas a partir desse critério como pressuposto para o desenvolvimento.

6 Estudo significativo para esta questão e que enfoca a formação do Consórcio Intermunicipal no grande ABC, na Região Metropolitana de São Paulo, foi realizado por Abrucio e Soares (2001). 
Contribuíram para esta visão ampliada do local - da escala municipal para a intermunicipal - pesquisas organizadas pelo IPEA sobre a caracterização da rede urbana brasileira e o Projeto Temático Rurbano ${ }^{7}$, financiado pela FAPESP e executado pelo Instituto de Economia da Unicamp. Esses estudos buscaram identificar as transformações ocorridas no espaço e forneceram subsídios à adoção do recorte territorial em algumas das políticas públicas, ao constatarem um país cada vez mais urbanizado, com a expansão dos aglomerados e centros urbanos e, como a outra face da moeda, tão rural, caracterização possível a partir de critérios distintos e que superam a sua identificação com o setor agropecuário.

A distinção entre municípios rurais e urbanos passou, assim, a ser uma variável utilizada por vários órgãos governamentais para se pensar os processos de desenvolvimento em uma federação tão heterogênea. A constatação de um “vazio microrregional”, isto é, a ausência de políticas direcionadas de forma articulada a conjuntos de municípios, preponderantemente de baixo contingente populacional e com perfil rural, se configurou como um dos passos iniciais para serem propostas ações territoriais como meios de se promover a dinamização de áreas consideradas estagnadas.

Dessa forma, são os territórios economicamente deprimidos, isto é, o conjunto de municípios que apresentam baixo ritmo de crescimento e potencial de desenvolvimento, medido pelo Índice de Desenvolvimento Humano (IDH), os novos espaços prioritários para que sejam estimulados novos arranjos socioprodutivos (ORTEGA, 2008, p. 17).

Essa orientação, originada nos países desenvolvidos e disseminada por meio das agências multilaterais e universidades, traz embutida a noção de multifuncionalidade da agricultura e a pluriatividade dos agricultores.

Por multifuncionalidade da agricultura entende-se a produção de bens imateriais que exercem funções não mercantis de caráter social, cultural e ambiental, e que geram efeitos positivos

\footnotetext{
7 O projeto foi conduzido por pesquisadores da Unicamp em parceria com outras instituições a partir da segunda metade da década de 1990 com o objetivo de verificar as mudanças no meio rural, principalmente no que concerne ao emprego e renda, gerando um conjunto de publicações que caracterizassem os distintos espaços rurais no Brasil.

8 Em dezembro de 2002 foi publicada a versão final do Plano Nacional de Desenvolvimento Rural Sustentável elaborado pelo Conselho Nacional de Desenvolvimento Rural Sustentável (CNDRS, 2002). O enfoque do meio rural como territorial, e não setorial, enseja orientações no sentido de articular setores do mercado, sociedade e poderes públicos municipais em direção a uma atuação no nível microrregional ou “territórios geosocioambientais”. A constatação de lacunas entre as dimensões mesorregional e municipal, e a criação de novas institucionalidades participativas nos territórios, com a finalidade de promover a sua dinamização e desenvolvimento, é a tônica do documento.
} 
para toda a sociedade ${ }^{9}$ (BONNEL e MALUF, 2007, p. 218). O Estado, nesse contexto, pode atuar mais incisivamente ao incentivar novas formas produtivas e corrigindo distorções de mercado, ou exercer um papel regulador a partir das demandas estabelecidas socialmente (BONNEL e MALUF, 2007, p. 220).

No Brasil, as ações estatais enquadram-se no primeiro caso, diferenciando-se as políticas direcionadas ao agronegócio daquelas voltadas à agricultura familiar. Com o objetivo de promover a inserção mercantil dos pequenos produtores e estimular novas atividades que se desenvolvam no espaço rural, foi criado o PRONAT e, mais recentemente, o Programa Territórios da Cidadania. Esses programas associam a multifuncionalidade da agricultura com a noção de pluriatividade do agricultor.

As transformações na estrutura produtiva das atividades agropecuárias, aliadas à expansão e intensificação do processo de urbanização, assim como o próprio desenvolvimento técnico e tecnológico possibilitaram uma aproximação maior entre as atividades ditas "urbanas” e "rurais”. Assim como na cidade existem hortas em meio a avenidas e serviços que são oferecidos à população que reside no meio rural, esta última também não restringe a utilização da sua força de trabalho a setores determinados, ou seja, as cidades não se definem pela indústria e nem o campo pela agricultura (ABRAMOVAY, 2003; VEIGA, 2003).

A concepção do espaço rural como continuidade do meio urbano orientou a atribuição de relevância à questão da pluriatividade; isto é, a coexistência de atividades agrícolas com as não agrícolas exercidas por segmentos dos agricultores familiares residentes no meio rural. $\mathrm{O}$ trabalhador, portanto, ao direcionar sua força de trabalho para a agroindústria, prestação de serviços de vários tipos ou outras ações correlacionadas, imbui-se de possibilidades de aumentar a sua renda e permanecer no meio rural (SILVA, 1997, p. 15).

Portanto, a caracterização dos municípios como rurais - considerados regionalmente e compreendendo tanto os centros urbanos como as áreas rurais -, a valorização multifuncional das atividades relacionadas ao setor agropecuário (multifuncionalidade) e a constatação de um novo perfil do trabalhador rural (pluriativo) são fatores fundamentais para a proposição de projetos de desenvolvimento que sejam formulados e implementados territorialmente, a partir de orientações que visam à descentralização das políticas com a participação da sociedade, premissas da abordagem territorial do desenvolvimento.

9 Abramovay (2003, p. 144) enfatiza a dimensão valorativa contida no conceito de multifuncionalidade. Para o autor, a preservação do meio natural e cultural alia-se ao fortalecimento do tecido social, com novos atores participando ativamente da gestão dos espaços rurais. 
Além de uma escala, o território é também um campo onde se estabelecem relações de poder, ou seja, “(...) uma arena de disputas de visões de mundo, interesses de atores e alianças políticas visando ao exercício do poder através da dominação” (SCHNEIDER, 2004, p. 109).

A criação de arenas específicas abarcando as demandas e a participação de atores oriundos da sociedade, mercado e estado, e a ênfase nas especificidades de cada região constituem o território de um modo característico de expressar as articulações entre o local-municipal, o regional e o nacional, com a variável espacial adquirindo relevância nas estratégias de desenvolvimento local. Nessa perspectiva, a contribuição de uma nova forma de negociação dos conflitos, compreendendo distintos níveis institucionais e rompendo com formas tradicionais de controle, permitiu a construção da noção de “governança de múltiplo nível” (SOUZA, 2002, p. 433).

A proposta que surgiu em torno da convergência dos eixos “desenvolvimento local-regional” e "abordagem territorial do desenvolvimento”, utilizada pelo Ministério do Desenvolvimento Agrário (MDA), está associada às propostas metodológicas e políticas adotadas e sugeridas pela Organização para a Cooperação e Desenvolvimento Econômico (OCDE) do início dos anos 1990, que tinham como objetivo comparar os espaços rurais diferenciados dos diversos países que compõem esta organização ${ }^{10}$, utilizando-se os critérios de tamanho populacional e densidade demográfica para analisar sua configuração territorial.

No âmbito da União Europeia, a Política Agrária Comum previu estímulos à cooperação entre municípios e lugares distintos de modo a possibilitar o desenvolvimento regional, com a elaboração de projetos inovadores viabilizando a dinamização dos territórios sem exercerem uma restrição ao setor agropecuário (ORTEGA, 2008).

No Brasil, as origens da abordagem territorial do desenvolvimento no meio rural remontam à execução do Programa Nacional de Agricultura Familiarr11 (PRONAF).

Com atividades iniciadas em 1996, o PRONAF foi concebido no âmbito do governo federal para fortalecer a agricultura familiar e promover a sua inserção competitiva nos mercados,

10 Sobre a abordagem territorial utilizada pela OCDE, estamos nos baseando em Schneider (2004), Veiga (2003) e Abramovay (2003). Em nível regional ou territorial, definido de acordo com a organização políticoadministrativa dos distintos países, estabelece-se a classificação: a) regiões essencialmente rurais: quando mais da metade da população da área reside em unidades de base rural; b) regiões relativamente rurais: quando entre $15 \%$ e $50 \%$ da população vive em áreas rurais; c) regiões essencialmente urbanas: quando menos de $15 \%$ da população regional mora em unidades de base rural.

11 O Programa de Valorização da Pequena Produção Rural (PROPAP) é considerado o precursor do PRONAF. Foi executado em 2004 pelo Ministério da Agricultura. Uma avaliação do PRONAF em relação aos estados, regiões e famílias atendidas pode ser obtida em IPEA (2005). 
facilitando o acesso ao crédito rural para investimento e custeio (PRONAF-C). Outra linha do PRONAF teve por objetivo o financiamento de infraestrutura e serviços em municípios selecionados pelo Conselho Nacional do Programa(PRONAF-M). Ainclusão para orecebimento de recursos a fundo perdido exigia a elaboração de Planos Municipais de Desenvolvimento Rural (PMDR), com a participação dos agricultores familiares e aprovados pelos Conselhos Municipais de Desenvolvimento Rural (CMDR) ${ }^{12}$ (ABRAMOVAY e VEIGA, 1998).

Os municípios que apresentassem taxas de distribuição fundiária - empreendimentos agropecuários de pequeno porte - mais pulverizadas em relação ao total estadual, taxas de urbanização menores do que a média do estado e as mais baixas taxas de produtividade agrícola, também em comparação ao âmbito estadual, foram considerados prioritários pelo PRONAF, ou seja, os municípios mais pobres e periféricos ${ }^{13}$ - e não necessariamente aqueles com maior presença de agricultores familiares e/ou com possibilidades de participar da elaboração de planos de desenvolvimento (ABRAMOVAY e VEIGA, 1998, p. 9).

A experiência obtida com a execução do PRONAF-M permitiu a revisão das orientações acerca do fato de os "municípios mais pobres e periféricos" - ou seja, municípios tipificados como rurais - promoverem, isoladamente, o seu desenvolvimento, seja em função de seus limites financeiros e técnicos, seja pela importância do entorno regional para potencializar os recursos existentes. As articulações intermunicipais foram, assim, incentivadas como instrumento para o fortalecimento dos territórios, ampliando-se a visão sobre as características do "rural", reforçando-se a complementaridade existente entre campo, cidade/rural e urbano ${ }^{14}$.

A partir de 2002 criou-se uma nova modalidade de ações direcionadas à Assistência Financeira a Projetos de Infraestrutura e Serviços, no âmbito do PRONAF, apoiando o desenvolvimento microrregional por meio de consórcios ou associações municipais. Na avaliação dos gerentes do programa, foi diagnosticado que o potencial de abrangência dessas ações era muito maior

\footnotetext{
12 O processo de aprovação envolvia a participação dos conselhos e secretarias estaduais e implicava benefícios como rede de energia elétrica, irrigação e habitação rural. Avaliação do PRONAF-C e PRONAF-M, entre 1996 e 1998, foi efetuada por Abramovay e Veiga (1999).

${ }^{13}$ Municípios com índices significativos de pobreza rural e com mais carências nas áreas de saúde, educação e infraestrutura. Em 2002, no entanto, um estudo publicado sugeriu a revisão dos critérios para seleção dos municípios beneficiários do PRONAF-M, pois o valor obtido pela produção industrial e dos serviços, ao não ser contabilizado, provocava distorções, apresentando municípios dotados de mais recursos sendo mais beneficiados em detrimento dos demais (PRONAF, 2002, p. 34).

14 Outros programas foram implementados no decorrer da década de 1990, como, por exemplo, a iniciativa denominada "Comunidade Ativa”, vinculada ao programa Comunidade Solidária para a elaboração e execução de projetos de desenvolvimento local integrado e sustentável.
} 
do que o contemplado até então ${ }^{15}$. Para promover esses objetivos, a partir de 2003 o PRONAF-M passou a ser gerenciado pela Secretaria de Desenvolvimento Territorial do Ministério do Desenvolvimento Agrário (SDT/MDA), criada neste mesmo ano para incentivar a dinamização de territórios rurais.

O PRONAF, na linha destinada a apoiar a infraestrutura municipal, pode ser considerado um instrumento utilizado pelo governo federal para induzir a descentralização de políticas direcionadas ao desenvolvimento rural. De acordo com Ortega (2008, p. 131):

Os municípios rurais deprimidos que eram contemplados pelo PRONAF Infraestrutura e Serviços em larga medida constituíram os territórios rurais do MDA, uma experiência de consórcios intermunicipais, com o intuito, por exemplo, de que os investimentos não fossem pulverizados nos municípios, mas, sim, alocados a iniciativas que aproveitassem a sinergia gerada por uma ação mais abrangente entre eles.

Constata-se uma nova visão do rural fundamentada nos critérios indicados por Veiga (2003), ou seja, densidade demográfica, tamanho populacional dos municípios e localização, e que se baseia nas políticas adotadas e referenciadas pelos países desenvolvidos, articuladas em torno da abordagem territorial do desenvolvimento.

A proposta dos territórios rurais constitui-se numa estratégia de estímulo à cooperação intermunicipal por meio da integração de espaços rurais e urbanos e dos níveis de governo, prevendo-se a gestão decisória compartilhada entre estado e sociedade, a denominada gestão social. Assim, orienta-se o desenvolvimento local não mais a partir de uma escala municipal, visão hegemônica na década de 1990, mas intermunicipal, abrangendo-se, assim, conjuntos de municípios que atuem de forma articulada.

\section{O programa territórios da cidadania e o território integração norte pioneiro (PR)}

O diagnóstico sobre a insuficiência de políticas públicas direcionadas ao interior brasileiro, o aumento da pobreza na década de 1990 e a persistência de desigualdades regionais, setoriais, sociais e econômicas resultaram na decisão governamental de formular uma proposta articuladora das políticas nacionais com as locais, abrangendo tanto o meio rural

15 Para o ano de 2001, um total de 1.251 municípios foi abrangido, mas cerca de 4.500 foram considerados predominantemente rurais. Uma das ações para alcançá-los previa o aperfeiçoamento das relações institucionais entre as três esferas de governo (LOPES, 2002).

CADERNOS GESTÃo PÚBliCA E CIDADANIA, V. 14, N. 55 - JUL./DEZEMBRo DE 2009 
como os centros urbanos, consubstanciada no Programa Territórios da Cidadania (SDT/MDA, 2005, p. 9).

Esse Programa, concebido como estratégia de desenvolvimento regional proposta pelo governo federal no âmbito do Ministério do Desenvolvimento Agrário ${ }^{16}$ (MDA), parte da premissa de que o desenvolvimento rural deve ser pensado em um quadro territorial no qual a elaboração descentralizada de projetos é mais eficiente para potencializar e valorizar elementos locais e regionais. A dimensão territorial do desenvolvimento é ressaltada para indicar a importância de se estimularem os vários setores produtivos de forma integrada, a articulação entre as diversas políticas setoriais, bem como a inclusão de toda a população residente nessas áreas. Com efeito:

O enfoque territorial é uma visão essencialmente integradora de espaços, atores sociais, agentes, mercados e políticas públicas de intervenção. Busca a integração interna dos territórios rurais e, desses com o restante da economia nacional, sua revitalização e reestruturação progressiva, assim como a adoção de novas funções e demandas (SDT/ MDA, 2008, p. 21).

O território entendido como um recorte espacial para definir a incidência das ações governamentais engloba aspectos socioculturais, ambientais e produtivos que possibilitam a aproximação e a cooperação entre os atores locais e os municípios envolvidos e "unidos pelas mesmas características econômicas e ambientais que tenham identidade e coesão" (TERRITÓRIOS, 2008, p. 2). Esses municípios, a partir dos critérios de tamanho e densidade demográfica, agregados em escalas mais amplas - microrregiões - inserem-se em áreas "que podem ser caracterizadas como 'essencialmente rurais', incluindo as respectivas cidades de médio e pequeno porte” (TERRITÓRIOS, 2008, p. 16-17).

Os critérios para se definir o reconhecimento oficial do território e sua seleção para o Programa são: a) menor Índice de Desenvolvimento Humano (IDH); b) maior número de municípios com baixo dinamismo econômico; c) áreas com expressiva participação de assentamentos da reforma agrária, agricultores familiares, famílias de pescadores, quilombolas, terras indígenas e beneficiários do programa Bolsa Família; d) maior organização social e e) ao menos um território por estado da federação (TERRITÓRIOS, 2008, p. 2-3).

16 Além do Ministério de Desenvolvimento Agrário, os Ministérios da Integração Nacional, do Trabalho e do Meio Ambiente possuem também projetos fundamentados na abordagem territorial. Também cabe mencionar a existência dos Consórcios de Segurança Alimentar (CONSADS), geridos pelo Ministério do Desenvolvimento Social e operando por meio de arranjos sociais territoriais, utilizando a mesma matriz que estrutura o programa Territórios da Cidadania (ORTEGA, 2008, p. 174). 
As ações envolvem 19 ministérios (consideradas como tais as Secretarias Especiais de Políticas para Mulheres, de Aquicultura e Pesca e de Promoção da Igualdade Racial) e os Bancos do Brasil, da Amazônia, do Nordeste, Nacional de Desenvolvimento Econômico e Social e a Caixa Econômica Federal, que articulam as suas atividades em três eixos: a) apoio às atividades produtivas; b) cidadania e acesso a direitos e c) qualificação da infraestrutura (TERRITÓRIOS, 2008).

O programa é complexo não apenas pelos seus propósitos que visam promover o desenvolvimento nas dimensões econômica, sociocultural, ambiental e político-institucional, mas, principalmente, porque reforça o caráter federativo ao combinar ações da União, dos governos estaduais e municipais.

Cada órgão do governo federal propõe um conjunto de ações para o território. Quando o programa é lançado nas comunidades, as reuniões entre a sociedade e os representantes das três esferas de governo devem ser efetuadas para definir o plano de desenvolvimento, que pode incluir ações conjuntas com os governos estaduais e municipais. Definido o plano de intervenção, a execução e o controle das obras podem ser realizados por meio de um portal na internet ${ }^{17}$, garantindo a participação e a transparência das ações.

A participação das três esferas de governo é formalizada por meio de um Acordo de Cooperação Federativa, assinado por um representante do Governo Estadual, um do governo estadual e pelo(s) representante(s) do(s) território(s). Embora os documentos institucionais disponibilizados pelo Ministério do Desenvolvimento Agrário (MDA) enfatizem a dimensão ascendente do programa - da participação popular para a institucionalidade territorial e desta, passando pelo estado, à União -, o acompanhamento dos trabalhos na constituição e formalização do Território Integração Norte Pioneiro contradiz essa perspectiva.

A questão das relações intergovernamentais e de sua coordenação constitui e perpassa a própria formação dos territórios, embora não seja o único fator que interfira para o êxito de ações. A promoção do desenvolvimento local a partir das articulações intermunicipais, o delineamento das condições para que elas se desenvolvam com estabilidade e sem conflitos e com autonomia territorial são condições que vão determinar se a gestão é efetivamente social, ou se ocorre centralização das decisões em outras esferas de governo.

O enfoque territorial subjacente à lógica de descentralização de políticas tem por objetivos contemplar: a) a dinamização das atividades econômicas; b) a infraestrutura física; c) a gestão

17 Disponível em: http://www.territoriosdacidadania.gov.br. Acesso em 12 fev. 2010. 
dos recursos naturais; d) a construção de espaços de identidade e e) novos espaços de governança (BONNEL e MALUF, 2007, p. 225).

Essa multiplicidade de objetivos coaduna-se com uma visão de desenvolvimento que supera a sua identificação com o crescimento econômico e o considera de forma multidimensional. Tal perspectiva, adotada pelo Estado brasileiro, principalmente desde a década de 1990, traz o entendimento de que "o desenvolvimento integrado é espacialmente localizado em cidades e regiões, e que programas de desenvolvimento devem ser sustentáveis” (FISCHER, 2002, p. 19).

Nesse sentido, o Programa Territórios da Cidadania busca contemplar, simultaneamente, duas lógicas distintas: a) o desenvolvimento orientado para a competição, principalmente na dimensão econômica, sob o discurso e propostas de novas formas de gestão e organização do sistema produtivo para um entorno territorial inovador e b) o desenvolvimento orientado para a cooperação e laços solidários, com o predomínio da lógica social sobre a econômica, como a que se verifica nos pressupostos da economia solidária (FISCHER, 2002, p. 20-21).

As ações propostas pelo Programa, ao incluir desde o apoio às atividades produtivas, à infraestrutura, à cidadania e aos direitos, até aquelas que se destinam a apoiar a gestão territorial, expressam essa composição normativa aparentemente contraditória, mas que se reforça mutuamente, constituindo-se assim uma referência para a análise de processos e dinâmicas territoriais concretas.

O Estado do Paraná tem uma produção expressiva no setor agropecuário. Embora a estrutura fundiária seja mais bem distribuída quando comparada a outros estados do país, há uma parcela de trabalhadores agrícolas - assalariados ou não - que encontram grandes dificuldades para superar a condição de pobreza. Em 2004, enquanto 64,2\% das famílias rurais tinham um rendimento salarial de até três salários mínimos, no meio urbano esse rendimento correspondia a 37,7\% das famílias (IPARDES, 2006, p. 17).

Outros dados ilustram a situação domiciliar rural no estado, tomando como referência o ano de 2004: a) apenas 8,74\% dos domicílios eram adequados ${ }^{18}$; b) Em torno de 73\% da população rural não havia concluído o ensino fundamental e c) houve relativa melhora no nível educacional entre 1999 e 2004, o que, porém, não se refletiu nos rendimentos auferidos - cerca de $60 \%$ da população rural teve renda inferior a um salário mínimo neste último ano (IPARDES, 2006).

18 Adequação refere-se ao acesso a bens e serviços e, portanto, a condições dignas de existência, tais como domicílio próprio, água canalizada, lixo coletado, banheiro, saneamento, energia, fogão, rádio ou tevê, geladeira (IPARDES, 2006, p. 25). 
O Projeto Paraná 12 meses, executado entre dezembro de 1997 e março de 2006, resultado de um convênio entre o governo do Estado do Paraná e o Banco Mundial, com o objetivo de aliviar a situação de pobreza rural no estado ao atuar nas áreas social, produtiva, de fortalecimento institucional e desenvolvimento tecnológico, procurou alterar essa realidade

Dado que os recursos para a geração de emprego e renda no meio rural foram direcionados à produção agrícola e não obtiveram sucesso em alterar a realidade, os avaliadores, ao final do programa, concluíram que esse caminho para o rural estava esgotado, devendo-se estimular as economias locais e não necessariamente as atividades agropecuárias.

Concomitantemente às ações do Programa, o Instituto Paranaense de Assistência Técnica e Extensão Rural (EMATER), como já mencionado anteriormente, desde 2000 vem atuando no norte pioneiro paranaense para a consecução de iniciativas territoriais, quais sejam: a) Vale do Rio das Cinzas; b) Território G5; c) Território Divisa Norte e d) Território Nordeste.

A iniciativa "Divisa Norte” foi a primeira a constituir-se, fruto de uma parceria entre a Federação dos Trabalhadores na Agricultura do Paraná (FETAEP) e da EMATER, para a capacitação de conselheiros, concomitantemente ao desenvolvimento de projetos voltados à dinamização das cadeias produtivas territoriais. Os territórios “G5” " "Vale do Rio das Cinzas”, onde também a FETAEP atuava, surgiram posteriormente. O território Nordeste foi constituído a partir das ações dos técnicos da EMATER. Cabe ressaltar que as políticas do governo federal a partir de 2003, com o PRONAT e o aporte de recursos aos territórios, contribuíram para que essas iniciativas se expandissem e se fortalecessem, o que pode ser constatado por meio da formação de consórcios intermunicipais.

No entanto, há problemas na integração dessas iniciativas em torno de uma concepção territorial mais ampla. Em entrevista com um dos representantes sindicais da iniciativa territorial do Vale do Rio das Cinzas, foi relatado que o fato de este território ter se constituído em Consórcio Intermunicipal possibilitaria a viabilização de projetos, independentemente do vínculo e da participação no Território Integração Norte Pioneiro. Essa declaração sugere uma visão restrita da ideia de participação, bem como de "integração" e de atuação conjunta para se promover o desenvolvimento em nível territorial.

O setor agropecuário é a base econômica dos municípios que compõem o Território. Produtos como café, leite, fruticultura, olericultura e, em algumas iniciativas territoriais, o apoio à agroindústria, têm sido a tônica dos projetos em curso, perpassando, em todas elas, a preocupação ambiental como, por exemplo, os projetos de revitalização da mata ciliar da bacia do Rio das Cinzas. 
Recentemente foi aprovado um projeto denominado "Inovação Tecnológica na Cadeia Produtiva do Café, Geração de Renda e Melhoria na Qualidade de Vida da Agricultura Familiar”, que visa superar gargalos relacionados à falta de infraestrutura para beneficiamento, classificação e padronização do café, bem como para a sua comercialização. Todos os 29 municípios serão contemplados com os recursos de R\$1.200.000,00 liberados pelo MDA, com contrapartida territorial de $\mathrm{R} \$ 24.000,00$.

No entanto, embora sejam as associações de produtores as gestoras do projeto, este tem como proponentes prefeituras ou consórcios. Ou seja, é possível pensar que, assim como a esfera federal e estadual possuem mais poder decisório em termos de sugerir uma dada configuração e composição territorial, assim também as prefeituras, isoladas ou conjuntamente, poderão sobrepor seus interesses aos das organizações gestoras. Apenas a execução do projeto e sua avaliação futura poderão indicar qual direcionamento se concretizará.

Além disso, embora o Programa Territórios da Cidadania preveja a integração entre o meio rural e urbano, e entre atividades agrícolas e não agrícolas, a própria presença do MDA com seus técnicos (ou articuladores territoriais), e a atuação da EMATER, indicam que, ao menos a curto e médio prazos, serão as atividades agropecuárias as privilegiadas, até porque os municípios que compõem o Território Integração Norte Pioneiro, em sua maioria, estão em grande parte estruturados por elas.

Várias reuniões e encontros, como a realização do I Fórum de Desenvolvimento Rural Sustentável, no município de São José da Boa Vista, em 2000, assim como cursos destinados à formação de agentes de desenvolvimento, oferecidos pela EMATER e MDA, nos anos seguintes, incentivaram a articulação entre os municípios. Através de um processo gradativo e negociado, essas ações culminaram na integração de todas essas iniciativas no Território Integração Norte Pioneiro, ao final de 2007.

Além das orientações efetuadas pelos órgãos estaduais e federais, os membros do Conselho Gestor Territorial Provisório entenderam que havia uma trajetória comum que, embora apresentasse especificidades em relação ao modo como as iniciativas territoriais se constituíram, conforme o conjunto de municípios em questão, a organização social, a realização de reuniões e o exercício do debate eram análogas a todas elas.

Com o início do Programa Territórios da Cidadania, a partir de 2008, dois territórios do Estado do Paraná foram contemplados: o Cantuquiriguaçu e o Vale do Ribeira. No decorrer desse mesmo ano, a expectativa de que mais dois ${ }^{19}$ fossem incorporados ao Programa levou a uma

19 Foram abrangidos pelo Programa, a partir de 2009, o Território Integração Norte Pioneiro e o Paraná Centro. 
mobilização dos sindicatos, prefeitos, extensionistas rurais, dentre outros, para que o Território Integração fosse um deles. Para tanto, exigiu-se uma moeda de troca, qual seja, a inclusão de dois novos municípios ao Território (Santo Antônio da Platina e Jacarezinho), polos regionais e administrados por prefeitas filiadas ao Partido dos Trabalhadores (PT).

Como esses municípios, desde o início dos trabalhos organizados pela EMATER e pela FETAEP, não desenvolveram atividades conjuntas - nem entre eles, nem com outros municípios circunvizinhos -, as iniciativas territoriais já constituídas e integradas em um único território desde 2007 não aceitaram a sua inclusão. No entanto, a possibilidade de se obter, por meio do Programa, mais recursos para todos os municípios abrangidos pelo Território se sobrepôs às discordâncias e a um eventual abalo na concepção de território como "construção social”.

A inclusão dos municípios-polo gera problemas para a efetividade da ideia de construção social, associada à articulação político-administrativa entre os municípios, devido a desigualdade de recursos entre aqueles que compõem o território. A relutância em aceitar a inclusão dos municípios mais relevantes em termos regionais também se deu em virtude do desequilíbrio que tal inserção ocasionaria, em termos políticos, econômicos e populacionais, segundo o depoimento de um ex-prefeito da região.

Foram verificados problemas a partir do acompanhamento das reuniões relativas à constituição do Conselho Territorial ${ }^{20}$. As dificuldades de participação da sociedade - por falta de tempo e recursos para o deslocamento, quando não ruídos nos processos de comunicação - resultam no fato de que, comumente, a maior parte dos presentes constituiu-se de técnicos da EMATER e, em menor medida, de representantes municipais e sindicais. Estes, por mais que demonstrassem interesse em que o território adquirisse autonomia, isto é, que fosse apropriado pela sociedade, acabaram conduzindo as reuniões, balizados pelos seus próprios conhecimentos e posições, norteando, dessa forma, a definição das estratégias com dificuldades visíveis de se incluírem outros grupos ou organizações na gestão territorial.

Também é importante ressaltar que, ainda que desde 2009 o Território Integração Norte Pioneiro participe do Programa Territórios da Cidadania, o Conselho Territorial institucionalidade criada para mediar os conflitos, estabelecer consensos e definir prioridades - concluiu a sua composição e formalização apenas em outubro desse mesmo ano. Isso significa que as decisões, a elaboração de projetos visando à obtenção de recursos e outras negociações territoriais têm se dado por intermédio de um grupo restrito, o que gera questionamentos sobre a efetivação de uma gestão social democrática.

${ }^{20}$ Dados oriundos das atas relativas à realização de reuniões ordinárias e extraordinárias do Conselho Estadual de Agricultura Familiar e Desenvolvimento Rural (PR).

CADERNOS GESTÃo PÚBLICA E CIDADANIA, V. 14, N. 55 - JUL./DEZEMBRO DE 2009 
Outra questão importante a ser ressaltada relaciona-se à matriz de ações propostas tanto pelo governo federal como estadual. Muitos dos investimentos já estão no orçamento, como aqueles oriundos do programa Bolsa Família e os Benefícios de Prestação Continuada, dentre outros que não se configurarem como recursos novos. Os participantes dos Conselhos Territoriais não deliberam em todas as situações. Isso significa que já há uma definição prévia sobre quais as prerrogativas do Conselho em cada caso, ações consultivas ou deliberativas, de articulação ou de controle social, sobressaindo-se as duas últimas.

Acrescente-se, ainda, que embora os documentos do governo ressaltem a importância de se estabelecer territorialmente os rumos do desenvolvimento, ou seja, a definição do para onde se vai e quais os caminhos para se alcançar os objetivos definidos - o que implica a priorização de ações, setores e atores capazes de articular os distintos interesses em direção a uma convergência política - este encaminhamento ainda não se concretizou no Território Integração Norte Pioneiro. O que se torna um agravante dessa situação é a contratação de uma empresa de consultoria pelo MDA para a elaboração do Plano Territorial de Desenvolvimento Rural Sustentável, a despeito das demandas do Território para que esta tarefa fosse elaborada por organizações da região, o que contradiz o pressuposto de uma estratégia de desenvolvimento que parte da sociedade em direção ao estado.

\section{Considerações finais}

O programa Territórios da Cidadania tem enfatizado a importância de processos cooperativos para o desenvolvimento ao enfocar a “construção social” dos territórios. No entanto, o modo pelo qual se deu a inclusão dos dois novos municípios no Território Integração Norte Pioneiro, que já apresentava uma configuração determinada, assim como os processos por meio dos quais vêm se concretizando as matrizes de ações indicam que essa lógica refere-se mais à descentralização de ações no meio rural, reforçando-se vertical e horizontalmente a integração federativa, do que propriamente a gestão social.

Os projetos que vêm sendo executados em âmbito territorial não resultam de objetivos definidos no Plano Territorial de Desenvolvimento Sustentável, até porque este ainda não foi formulado. O que se observou é que há uma preocupação na elaboração de projetos para a obtenção de recursos, enquanto a efetividade da gestão social acaba se subordinando a esses objetivos.

Embora novos espaços institucionais tenham se constituído em nível intermediário entre sociedade e estado, buscando preencher o “vazio microrregional”, a referência ao exercício de 
uma cidadania ativa deixa a desejar, tanto em função do modo pelo qual as articulações vêm sendo conduzidas pelos agentes estatais, como pelas próprias prerrogativas do Conselho Territorial; observam-se ações restritivas em termos deliberativos e consultivos, predominando as ações de controle social e de articulação. A atuação do Conselho Territorial provisório não expressou a capacidade de propor uma agenda e, dada a sua formalização recente, além do grande número de participantes (88 no total), oriundos de 29 municípios, a tendência é o surgimento de obstáculos para a reversão desse quadro.

A análise realizada até o momento aponta para a hipótese, a ser desenvolvida futuramente, de que o Programa acaba por priorizar a geração de renda sem que outras dimensões do desenvolvimento sejam, necessariamente, contempladas. Nesse sentido, a concepção de desenvolvimento como eliminação das privações de liberdade em todas as dimensões (SEN, 2000), que implica modificar as condições estruturais de uma dada organização social, não indica possibilidades de concretização, ao menos em médio prazo, no que tange às atuais políticas baseadas no enfoque territorial e direcionadas ao meio rural.

\section{Referências}

ABRAMOVAY, R. O futuro das regiões rurais. Porto Alegre: UFRGS, 2003.

ABRAMOVAY, R.; VEIGA, J. E. Novas instituições para o desenvolvimento rural: o caso do Programa Nacional de Agricultura Familiar (PRONAF). Texto para discussão 641. IPEA, Brasília: 1998. Disponível em: http://www.ipea.gov.br. Acesso em: 30 nov. 2008.

ABRUCIO, F.; SOARES, M. Redes federativas no Brasil: cooperação intermunicipal no grande ABC. São Paulo: Fundação Konrad Adenauer, 2001.

BONNA, P.; MALUF, R. S. Do uso das noções de multifuncionalidade e território nas políticas agrícolas e rurais no Brasil. In: LIMA, N.; DELGADO, N. G.; MOREIRA, R. J. (Org.) Mundo rural IV - configurações rural-urbanas: poderes e políticas. Rio de Janeiro: Mauad, 2007.

CACCIA-BAVA, S. Desenvolvimento local: uma alternativa para a crise social? São Paulo em Perspectiva, v. 10, n. 3, p. 53-59, 1996.

CASTELLS, M; BORJA, J. As cidades como atores políticos. Novos Estudos, n. 45, p. 152-166, 1996.

CNDRS. Conselho Nacional de Desenvolvimento Rural Sustentável. Plano Nacional de Desenvolvimento Rural Sustentável. Brasília, Ministério do Desenvolvimento Agrário. 


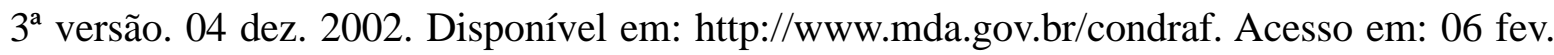
2009. p. 217-235.

FISCHER, T. Poderes locais, desenvolvimento e gestão: introdução a uma agenda. In: FISCHER, T. (Org.) Gestão do desenvolvimento e poderes locais: marcos teóricos e avaliação. Salvador: Casa da Qualidade, 2002.

IPARDES. Instituto Paranaense de Desenvolvimento Econômico e Social. Leituras regionais: mesorregião geográfica norte pioneiro paranaense. Curitiba: IPARDES/BRDE, 2004.

IPARDES. Os vários Paranás: identificação de espacialidades socioeconômico-institucionais como subsídios a políticas de desenvolvimento regional. Curitiba: IPARDES, 2006.

IPARDES. Programa Paraná 12 meses: avaliação final de impacto socioeconômico da atividade em comunidades rurais pobres. Curitiba: IPARDES, 2006. 138 p.

IPARDES. Diagnóstico socioeconômico do Território Norte Pioneiro Paranaense: $1^{\text {a }}$ fase, caracterização global. Curitiba: IPARDES, 2007. 154 p.

IPARDES. Projeto Inclusão e Desenvolvimento Territorial: dinâmica econômica e desigualdades regionais no Paraná. Nota técnica. Curitiba: IPARDES, 2009. 28 p. Disponível em: http://www.ipardes.pr.gov.br. Acesso em: 10 nov. 2009.

IPEA. Políticas Sociais: acompanhamento e análise. Brasília: IPEA, n. 10, fev. 2005.

IPEA; IBGE; UNICAMP; NESUR; IPARDES. Caracterização e tendências da rede urbana do Brasil: redes urbanas regionais Sul. Brasília: IPEA, 2000. Série caracterização e tendências da rede urbana no Brasil, v. 6.

LOPES, R. P. Agricultura familiar. Brasília: MDA/PRONAF, 2002. Disponível em: http:// www.abrasil.gov.br. Acesso em: 19 jan. 2009.

ORTEGA, A. C. Territórios deprimidos: desafios para as políticas de desenvolvimento rural. Campinas: Alínea; Uberlândia: Edufu, 2008.

PRONAF. Planos municipais de desenvolvimento rural. Cadernos de Capacitação, n. 4, Brasília: MDA/SAF, 2002. 35 p.

SACHS, I. Desenvolvimento includente, sustentável, sustentado. Rio de Janeiro: Garmond, 2004.

SANTOS, B. S.; RODRIGUES, C. Introdução: para ampliar o cânone da produção. In: SANTOS, B. S. (Org.) Produzir para viver: os caminhos da produção não capitalista. Rio de Janeiro: Civilização Brasileira, 2002. p. 23-64.

CADERNOS GESTÃo PÚBliCA E CIDADANIA, V. 14, N. 55 - JUL./DEZEMBRO DE 2009 
SCHNEIDER, S.; TARTARUGA, I. G. P. Território e abordagem territorial: das referências cognitivas aos aportes aplicados à análise dos processos sociais rurais. Raízes, v. 23, n. 2, p. 99-116, 2004.

SCHNEIDER, S. A abordagem territorial do desenvolvimento rural e suas articulações externas. Sociologias, v. 6, n. 11, p. 88-125, 2004.

SDT/MDA. Secretaria de Desenvolvimento Territorial/Ministério do Desenvolvimento Agrário. Referências para uma estratégia de desenvolvimento rural sustentável no Brasil. Série Documentos SDT n. 1. Brasília: SDT/MDA, 2005 (publicado originalmente em 2003). Disponível em: http://www.mda.gov.br. Acesso em: 03 jan. 2008.

SEN, A. Desenvolvimento como liberdade. São Paulo: Cia das Letras, 2000.

SILVA, J. G. O novo rural brasileiro. Nova Economia, v. 7, n. 1, p. 43-81, 1997.

SILVA, J. G. Novos e velhos mitos do rural brasileiro. Estudos Avançados, v. 15, n. 43, p. 37-50, 2001.

SOUZA, C. Governos e sociedades locais em contextos de desigualdades e de descentralização. Ciência \& Saúde Coletiva, v. 7, n. 3, p. 431-442, 2002.

TERRITÓRIOS da Cidadania: Brasil 2008. Disponível em:

http://www.territoriosdacidadania.gov.br. Acesso em: 05 maio 2008.

VEIGA, J. E. Cidades imaginárias: o Brasil é menos urbano do que se calcula. 2. Ed. Campinas: Autores associados, 2003.

VEIGA, J. E. Pobreza rural, distribuição de riqueza e crescimento: a experiência brasileira. Disponível em: http://www.nead.org.br. Acesso em: 06 dez. 2008.

\section{Artigo recebido em 15/09/2009. Aprovado em 21/12/2009.}

